\title{
On high-order compact schemes for the multidimensional time-fractional Schrödinger equation
}

\author{
Rena Eskar ${ }^{1 *} \mathbb{D}$, Xinlong Feng ${ }^{1}$ and Ehmet Kasim ${ }^{1}$
}

\section{"Correspondence:}

renaeskar@xju.edu.cn

${ }^{1}$ College of Mathematics and

System Sciences, Xinjiang

University, Urumqi, P.R. China

\section{Springer}

\begin{abstract}
In this article, some high-order compact finite difference schemes are presented and analyzed to numerically solve one- and two-dimensional time fractional Schrödinger equations. The time Caputo fractional derivative is evaluated by the $L 1$ and $L 1-2$ approximation. The space discretization is based on the fourth-order compact finite difference method. For the one-dimensional problem, the rates of the presented schemes are of order $O\left(\tau^{2-\alpha}+h^{4}\right)$ and $O\left(\tau^{3-\alpha}+h^{4}\right)$, respectively, with the temporal step size $\tau$ and the spatial step size $h$, and $\alpha \in(0,1)$. For the two-dimensional problem, the high-order compact alternating direction implicit method is used. Moreover, unconditional stability of the proposed schemes is discussed by using the Fourier analysis method. Numerical tests are performed to support the theoretical results, and these show the accuracy and efficiency of the proposed schemes.
\end{abstract}

Keywords: Time-fractional Schrödinger equation; $L 1-2$ and $L 1$ formulas; Compact finite difference method; ADI; Stability

\section{Introduction}

Nowadays fractional differential equations have been widely studied in many fields, owing to their diverse applications in physics, biology, chemistry, mechanics, and finance theory [1-9]. These applications have contributed to the emergence of various fractional differential equations in the mathematical and physical world. In [10-14], the authors have published some new results of fractional operators and their applications. In fact, it is difficult to gain analytic solutions of fractional differential equations. Therefore, it is important to obtain highly accurate numerical methods for solving these fractional differential equations.

For time-fractional partial differential equations, many different numerical methods have been introduced, including theoretical analysis and numerical computing. Authors in $[15,16]$ have proposed various spatial second-order finite difference methods for a onedimensional problem. For two-dimensional time-fractional partial differential equations, several numerical methods have been proposed $[17,18]$. To improve the numerical accuracy, some fourth-order compact finite difference methods have been proposed for oneand two-dimensional time-fractional partial differential equations. Cui [19] constructed

(c) The Author(s) 2020. This article is licensed under a Creative Commons Attribution 4.0 International License, which permits use, sharing, adaptation, distribution and reproduction in any medium or format, as long as you give appropriate credit to the original author(s) and the source, provide a link to the Creative Commons licence, and indicate if changes were made. The images or other third party material in this article are included in the article's Creative Commons licence, unless indicated otherwise in a credit line to the material. If material is not included in the article's Creative Commons licence and your intended use is not permitted by statutory regulation or exceeds the permitted use, you will need to obtain permission directly from the copyright holder. To view a copy of this licence, visit http://creativecommons.org/licenses/by/4.0/. 
high-order compact alternating direction implicit schemes for two-dimensional timefractional diffusion equations. Gao and Sun [20] focused on the study of spatial sixth-order accurate combined compact alternating direction implicit difference schemes for solving two-dimensional time-fractional advection-diffusion equations. Zhai and Feng [21] investigated several compact alternating direction implicit methods for a two-dimensional time-fractional diffusion equation.

In this paper, we consider the following multidimensional time-fractional Schrödinger equation (TFSE):

$$
i \frac{\partial^{\alpha} u(\mathbf{x}, t)}{\partial t^{\alpha}}=\nabla^{2} u(\mathbf{x}, t)+f(\mathbf{x}, t), \quad \mathbf{x} \in \Omega, t \in(0, T]
$$

with the initial and boundary conditions

$$
\begin{aligned}
& u(\mathbf{x}, 0)=u_{0}(\mathbf{x}), \quad \mathbf{x} \in \Omega, \\
& u(\mathbf{x}, t)=\varphi(\mathbf{x}, t), \quad \mathbf{x} \in \partial \Omega, t \in(0, T]
\end{aligned}
$$

where $\Omega$ is a rectangular domain in $\mathbf{R}^{d}(d=1,2), \partial \Omega$ is the boundary of $\Omega, i=\sqrt{-1}$, and $u_{0}$ and $f$ are known smooth functions. The fractional derivative $\partial^{\alpha} u(\mathbf{x}, t) / \partial t^{\alpha}$ is the $\alpha$ th order Caputo time fractional derivative defined by

$$
\frac{\partial^{\alpha} u(\mathbf{x}, t)}{\partial t^{\alpha}}=\frac{1}{\Gamma(1-\alpha)} \int_{0}^{t}(t-s)^{-\alpha} \partial_{s} u(\mathbf{x}, s) d s
$$

with $\alpha \in(0,1)$.

In recent years, some researchers have presented numerical solutions for the timefractional Schrödinger equation. Mohebbi et al. [22] investigated meshless method based on collocation method for the numerical solutions of time fractional nonlinear Schrödinger equation. Wei et al. [23] proposed an implicit fully discrete local discontinuous Galerkin method for the TFSE. Li et al. [24] proposed L1-Galerkin finite element method for the numerical and stability analysis of multidimensional TFSEs. In [25], the space-time Jacobi spectral collocation method is used to solve the time-fractional nonlinear Schrödinger equations subject to the appropriate initial and boundary conditions. Chen et al. [26] also proposed linearized compact alternating direction implicit schemes for nonlinear TFSEs.

The main purpose of this paper is to construct some efficient high-order compact difference schemes for solving TFSE (1.1) with (1.2) and (1.3). We apply the $L 1$ and $L 1-2$ formulas to approximate the time-fractional derivative and use compact operators to approximate spatial second-order derivatives. We treat the two-dimensional problem using the compact alternating direction implicit (ADI) scheme. The computational complexity is reduced to some extent. The $L 1$ formula is the main approximation formula for approximating the time-fractional derivative, in which the truncation error is $O\left(\tau^{2-\alpha}\right)[27,28]$. In [29], Gao et al. proposed a new difference analog of the Caputo fractional derivative with convergence order $O\left(\tau^{3-\alpha}\right)$, called the $L 1-2$ formula.

The remainder of our paper is organized as follows. In Sect. 2, we introduce some notations and useful results, and then two high-order compact finite difference schemes are 
constructed for the one-dimensional TFSE. We use the Fourier analysis method to investigate the stability of the two schemes. In Sect. 3, we extend our methods to the twodimensional case and propose two compact ADI difference schemes by adding the perturbation term. Furthermore, a stability analysis is presented. In Sect. 4, we present numerical examples and detailed numerical results to confirm our theoretical analysis. Finally, a brief conclusion is provided in Sect. 5.

\section{High-order compact difference schemes for the one-dimensional TFSE}

In this section, we consider the following one-dimensional (1D) TFSE:

$$
\begin{aligned}
& i \frac{\partial^{\alpha} u(x, t)}{\partial t^{\alpha}}=\frac{\partial^{2} u(x, t)}{\partial x^{2}}+f(x, t), \quad x \in \Omega=(0, L), t \in[0, T], \\
& u(x, 0)=u_{0}(x), \quad x \in \Omega, \\
& \left.u(x, t)\right|_{\partial \Omega}=\varphi(x, t), \quad(x, t) \in \partial \Omega \times(0, T],
\end{aligned}
$$

where $L$ and $T$ are positive constants. $u_{0}(x), \varphi(x, t)$, and $f(x, t)$ are given smooth functions.

We first present some notations and useful results, which provide the basis for the theoretical analysis of our numerical methods. Let $N_{x}$ and $N$ be two positive integers, $h=\frac{L}{N_{x}}$ be the spatial step size, and $\tau=\frac{T}{N}$ be the time step size. Define $\Omega_{h}=\left\{x_{j} \mid 0 \leq j \leq N_{x}\right\}$ with $x_{j}=j h$, and $\Omega_{\tau}=\left\{t_{n} \mid 0 \leq n \leq N\right\}$ with $t_{n}=n \tau$. Then the domain $[0, L] \times[0, T]$ is covered by $\Omega_{h} \times \Omega_{\tau}$. Let $\hat{u}=\left\{u_{j}^{n} \mid 0 \leq j \leq N_{x}, 0 \leq n \leq N\right\}$ be a grid function on $\Omega_{h} \times \Omega_{\tau}$, and define

$$
\left\{\begin{array}{l}
\delta_{x}^{2} u_{j}^{n}=\frac{1}{h^{2}}\left(u_{j-1}^{n}-2 u_{j}^{n}+u_{j+1}^{n}\right), \\
L_{x} u_{j}^{n}=\left(I+\frac{h^{2}}{12} \delta_{x}^{2}\right) u_{j}^{n} .
\end{array}\right.
$$

Next we introduce some useful results and design several compact finite difference schemes.

Lemma 2.1 (The $L 1$ formula, see $[30,31])$ Suppose that $\alpha \in(0,1)$ and $u(t) \in C^{2}[0, T]$. Then we have

$$
{ }_{0}^{C} \mathcal{D}_{t}^{\alpha} u\left(t_{n}\right)=\frac{1}{\tau^{\alpha} \Gamma(2-\alpha)}\left[a_{0} u^{n}-\sum_{l=1}^{n-1}\left(a_{n-l-1}-a_{n-l}\right) u^{l}-a_{n-1} u^{0}\right]+O\left(\tau^{2-\alpha}\right),
$$

where $a_{l}=(l+1)^{1-\alpha}-l^{1-\alpha}, l \geq 0$, and the coefficients $a_{l}$ satisfy

$$
\begin{aligned}
& 1=a_{0}>a_{1}>a_{2}>\cdots>a_{l}>\cdots \rightarrow 0, \\
& (1-\alpha)(l+1)^{-\alpha}<a_{l}<(1-\alpha) l^{-\alpha} .
\end{aligned}
$$

Lemma 2.2 (The $L 1-2$ formula, see [29]) Suppose that $\alpha \in(0,1)$ and $u(t) \in C^{3}[0, T]$. Then we have

$$
{ }_{0}^{C} \mathcal{D}_{t}^{\alpha} u\left(t_{n}\right)=\frac{1}{\tau^{\alpha} \Gamma(2-\alpha)}\left[c_{0} u^{n}-\sum_{l=1}^{n-1}\left(c_{n-l-1}-c_{n-l}\right) u^{l}-c_{n-1} u^{0}\right]+O\left(\tau^{3-\alpha}\right),
$$


where $c_{0}=a_{0}=1$ for $n=1$; and for $n \geq 2$,

$$
c_{l}= \begin{cases}a_{0}+b_{0}, & l=0, \\ a_{l}+b_{l}-b_{l-1}, & 1 \leq l \leq n-2, \\ a_{l}-b_{l-1}, & l=n-1,\end{cases}
$$

with

$$
\begin{aligned}
& a_{l}=(l+1)^{1-\alpha}-l^{1-\alpha}, \\
& b_{l}=\frac{1}{2-\alpha}\left[(l+1)^{2-\alpha}-l^{2-\alpha}\right]-\frac{1}{2}\left[(l+1)^{1-\alpha}-l^{1-\alpha}\right] .
\end{aligned}
$$

Now, we consider the derivation of the high-order compact finite difference schemes. Applying the fourth-order Padé scheme for the second-order derivative, we have

$$
\frac{\partial^{2} u}{\partial x^{2}}\left(x_{j}, t_{n}\right)=L_{x}^{-1} \delta_{x}^{2} u_{j}^{n}+O\left(h^{4}\right) .
$$

Using (2.7), we obtain the following semi-discrete fourth-order approximation for the 1D problem (2.1):

$$
i\left[{ }_{0}^{C} \mathcal{D}_{t}^{\alpha} u\right]_{j}^{n}=L_{x}^{-1} \delta_{x}^{2} u_{j}^{n}+f_{j}^{n}+O\left(h^{4}\right)
$$

Then, plugging (2.4)-(2.5) into (2.8) and neglecting the small truncation errors, we obtain the high-order compact scheme (CS1DI) for (2.1)-(2.3) as follows:

$$
\text { CS1DI: }\left\{\begin{aligned}
{\left[i a_{0}-\right.} & \left.\frac{12}{h^{2}} \tau^{\alpha} \Gamma(2-\alpha)\right] u_{j-1}^{1}+\left[10 i a_{0}+\frac{24}{h^{2}} \tau^{\alpha} \Gamma(2-\alpha)\right] u_{j}^{1} \\
& +\left[i a_{0}-\frac{12}{h^{2}} \tau^{\alpha} \Gamma(2-\alpha)\right] u_{j+1}^{1} \\
= & i a_{0} u_{j-1}^{0}+10 i a_{0} u_{j}^{0}+i a_{0} u_{j+1}^{0} \\
& +\tau^{\alpha} \Gamma(2-\alpha)\left[f_{j-1}^{1}+10 f_{j}^{1}+f_{j+1}^{1}\right], \quad n=1 \\
{\left[i a_{0}-\right.} & \left.\frac{12}{h^{2}} \tau^{\alpha} \Gamma(2-\alpha)\right] u_{j-1}^{n}+\left[10 i a_{0}+\frac{24}{h^{2}} \tau^{\alpha} \Gamma(2-\alpha)\right] u_{j}^{n} \\
& +\left[i a_{0}-\frac{12}{h^{2}} \tau^{\alpha} \Gamma(2-\alpha)\right] u_{j+1}^{n} \\
= & i\left[\sum_{l=1}^{n-1}\left(a_{n-l-1}-a_{n-l}\right) u_{j-1}^{l}+a_{n-1} u_{j-1}^{0}\right] \\
& +10 i\left[\sum_{l=1}^{n-1}\left(a_{n-l-1}-a_{n-l}\right) u_{j}^{l}+a_{n-1} u_{j}^{0}\right]+i\left[\sum_{l=1}^{n-1}\left(a_{n-l-1}-a_{n-l}\right) u_{j+1}^{l}\right. \\
& \left.+a_{n-1} u_{j+1}^{0}\right]+\tau^{\alpha} \Gamma(2-\alpha)\left[f_{j-1}^{n}+10 f_{j}^{n}+f_{j+1}^{n}\right], \quad 2 \leq n \leq N \\
u_{j}^{0}= & u_{0}\left(x_{j}\right), \quad 0 \leq j \leq N_{x} \\
u_{j}^{n}= & \varphi\left(x_{j}, t_{n}\right), \quad j \in \partial \Omega_{h}, 1 \leq n \leq N .
\end{aligned}\right.
$$

We now present the second difference scheme for (2.1)-(2.3). Substituting (2.4) and (2.6) into (2.8) and omitting the small terms, we obtain the second high-order compact scheme 
$(C S 1 D I I)$ in the form of

$$
\text { CS1DII: }\left\{\begin{aligned}
{\left[i c_{0}-\right.} & \left.\frac{12}{h^{2}} \tau^{\alpha} \Gamma(2-\alpha)\right] u_{j-1}^{1}+\left[10 i c_{0}+\frac{24}{h^{2}} \tau^{\alpha} \Gamma(2-\alpha)\right] u_{j}^{1} \\
& +\left[i c_{0}-\frac{12}{h^{2}} \tau^{\alpha} \Gamma(2-\alpha)\right] u_{j+1}^{1} \\
= & i c_{0} u_{j-1}^{0}+10 i c_{0} u_{j}^{0}+i c_{0} u_{j+1}^{0} \\
& +\tau^{\alpha} \Gamma(2-\alpha)\left[f_{j-1}^{1}+10 f_{j}^{1}+f_{j+1}^{1}\right], \quad n=1 ; \\
{\left[i c_{0}-\right.} & \left.\frac{12}{h^{2}} \tau^{\alpha} \Gamma(2-\alpha)\right] u_{j-1}^{n}+\left[10 i c_{0}+\frac{24}{h^{2}} \tau^{\alpha} \Gamma(2-\alpha)\right] u_{j}^{n} \\
& +\left[i c_{0}-\frac{12}{h^{2}} \tau^{\alpha} \Gamma(2-\alpha)\right] u_{j+1}^{n} \\
= & i\left[\sum_{l=1}^{n-1}\left(c_{n-l-1}-c_{n-l}\right) u_{j-1}^{l}+c_{n-1} u_{j-1}^{0}\right] \\
& +10 i\left[\sum_{l=1}^{n-1}\left(c_{n-l-1}-c_{n-l}\right) u_{j}^{l}+c_{n-1} u_{j}^{0}\right]+i\left[\sum_{l=1}^{n-1}\left(c_{n-l-1}-c_{n-l}\right) u_{j+1}^{l}\right. \\
& \left.+c_{n-1} u_{j+1}^{0}\right]+\tau^{\alpha} \Gamma(2-\alpha)\left[f_{j-1}^{n}+10 f_{j}^{n}+f_{j+1}^{n}\right], \quad 2 \leq n \leq N ; \\
u_{j}^{0}= & u_{0}\left(x_{j}\right), \quad 0 \leq j \leq N_{x}, \\
u_{j}^{n}= & \varphi\left(x_{j}, t_{n}\right), \quad j \in \partial \Omega_{h}, 1 \leq n \leq N .
\end{aligned}\right.
$$

From Lemma 2.1, Lemma 2.2, and (2.7), it is obvious that schemes CS1DI and CS1DII have truncation errors of order $O\left(\tau^{2-\alpha}+h^{4}\right)$ and $O\left(\tau^{3-\alpha}+h^{4}\right)$, respectively.

We now investigate the stability of the above schemes by using the Fourier analysis method. For the simplicity of illustration, we consider the case that $f(x, t)=0$.

Let the numerical solution be represented by

$$
u_{j}^{n}=v^{n} e^{i \theta j h}
$$

where $i=\sqrt{(-1)}, v^{n}$ is the amplitude at time $t_{n}$, and $\theta$ is the wave number in the $x$ direction. We define the discrete $L^{2}$ norm by $\left\|u^{n}\right\|_{L^{2}}^{2}=h \sum_{j=1}^{N_{x}}\left|u_{j}^{n}\right|^{2}$. For the fully discrete schemes CS1DI and CS1DII, we have the following stability results.

Theorem 1 Schemes CS1DI and CS1DII, defined by (2.9) and (2.10) respectively, are unconditionally stable for $\alpha \in(0,1)$.

Proof We will complete the proof using mathematical induction. For convenience, we only give the proof for scheme CS1DI, and the case for scheme CS1DII can be completed using a similar idea.

We rewrite (2.9) as follows:

$$
\left[12 i a_{0}+\left(i a_{0} h^{2}-12 \tau^{\alpha} \Gamma(2-\alpha)\right) \delta_{x}^{2}\right] u_{j}^{1}=\left[12 i a_{0}+i a_{0} h^{2} \delta_{x}^{2}\right] u_{j}^{0}
$$

for $n=1$, and for $n \geq 2$ we rewrite it as

$$
\begin{aligned}
& {\left[12 i a_{0}+\left(i a_{0} h^{2}-12 \tau^{\alpha} \Gamma(2-\alpha)\right) \delta_{x}^{2}\right] u_{j}^{n}} \\
& \quad=\left[12 i+i h^{2} \delta_{x}^{2}\right]\left[\sum_{l=1}^{n-1}\left(a_{n-l-1}-a_{n-l}\right) u_{j}^{l}+a_{n-1} u_{j}^{0}\right] .
\end{aligned}
$$


Substituting (2.11) into (2.12) and (2.13), we obtain

$$
\begin{aligned}
& {\left[12 i a_{0}-4 i a_{0} \sin ^{2} \frac{\theta h}{2}+\frac{48}{h^{2}} \tau^{\alpha} \Gamma(2-\alpha) \sin ^{2} \frac{\theta h}{2}\right] v^{1}} \\
& =\left[12 i a_{0}-4 i a_{0} \sin ^{2} \frac{\theta h}{2}\right] v^{0}
\end{aligned}
$$

and

$$
\begin{aligned}
& {\left[12 i a_{0}-4 i a_{0} \sin ^{2} \frac{\theta h}{2}+\frac{48}{h^{2}} \tau^{\alpha} \Gamma(2-\alpha) \sin ^{2} \frac{\theta h}{2}\right] v^{n}} \\
& \quad=\left[12 i-4 i \sin ^{2} \frac{\theta h}{2}\right]\left[\sum_{l=1}^{n-1}\left(a_{n-l-1}-a_{n-l}\right) v^{l}+a_{n-1} v^{0}\right] .
\end{aligned}
$$

Then

$$
v^{1}=\frac{\left[12 i a_{0}-4 i a_{0} \sin ^{2} \frac{\theta h}{2}\right]}{\left[12 i a_{0}-4 i a_{0} \sin ^{2} \frac{\theta h}{2}+\frac{48}{h^{2}} \tau^{\alpha} \Gamma(2-\alpha) \sin ^{2} \frac{\theta h}{2}\right]} v^{0} .
$$

Since $a_{0}=1$, we can easily obtain

$$
\left|v^{1}\right| \leq\left|v^{0}\right|
$$

Suppose that $\left|v^{m}\right| \leq\left|v^{0}\right|$ holds for $m=1,2, \ldots, n-1$. Then, using (2.15) and Lemma 2.1, we have

$$
\begin{aligned}
\left|v^{n}\right| & \leq \sum_{l=1}^{n-1}\left(a_{n-l-1}-a_{n-l}\right)\left|v^{l}\right|+a_{n-1}\left|v^{0}\right| \\
& \leq\left[\sum_{l=1}^{n-1}\left(a_{n-l-1}-a_{n-l}\right)+a_{n-1}\right]\left|v^{0}\right|=\left|v^{0}\right| .
\end{aligned}
$$

That is,

$$
\left|v^{n}\right| \leq\left|v^{0}\right|
$$

holds true for all $m=n$. Moreover, applying (2.16) and Parseval's equality, we obtain

$$
\begin{aligned}
\left\|u^{n}\right\|_{L^{2}}^{2} & =h \sum_{j=1}^{N_{x}}\left|u_{j}^{n}\right|^{2}=h \sum_{j=1}^{N_{x}}\left|v^{n} e^{i \theta j h}\right|^{2}=h \sum_{j=1}^{N_{x}}\left|v^{n}\right|^{2} \\
& \leq h \sum_{j=1}^{N_{x}}\left|v^{0}\right|^{2}=h \sum_{j=1}^{N_{x}}\left|v^{0} e^{i \theta j h}\right|^{2}=h \sum_{j=1}^{N_{x}}\left|u_{j}^{0}\right|^{2}=\left\|u^{0}\right\|_{L^{2}}^{2}, \quad n=1, \ldots, N,
\end{aligned}
$$

which proves that scheme CS1DI is unconditionally stable. Thus, the proof is completed. 


\section{High-order compact ADI schemes for the two-dimensional TFSE}

In this section, we develop two high-order compact ADI schemes for two-dimensional (2D) TFSE with the following initial and boundary conditions:

$$
\begin{aligned}
& i \frac{\partial^{\alpha} u(x, y, t)}{\partial t^{\alpha}}=\left(\frac{\partial^{2}}{\partial x^{2}}+\frac{\partial^{2}}{\partial y^{2}}\right) u(x, y, t)+f(x, y, t), \quad(x, y) \in \Omega, t \in(0, T], \\
& u(x, y, 0)=u_{0}(x, y), \quad(x, y) \in \Omega \\
& \left.u(x, y, t)\right|_{\partial \Omega}=\varphi(x, y, t), \quad(x, y, t) \in \partial \Omega \times(0, T]
\end{aligned}
$$

where $L$ and $T$ are positive constants, $\Omega=(0, L) \times(0, L) \cdot u_{0}(x, y), \varphi(x, y, t)$, and $f(x, y, t)$ are given smooth functions.

Let $M, N$ be positive integers, $h=\frac{L}{M}$ be the spatial step size, and $\tau=\frac{T}{N}$ be the time step size. Define $\Omega_{h}=\left\{\left(x_{j}, y_{k}\right) \mid 0 \leq j, k \leq M\right\}$ with $x_{j}=j h$ and $y_{k}=k h$; and $\Omega_{\tau}=\left\{t_{n} \mid 0 \leq n \leq N\right\}$ with $t_{n}=n \tau$. Then the domain $[0, L]^{2} \times[0, T]$ is covered by $\Omega_{h} \times \Omega_{\tau}$. Let $\hat{u}=\left\{u_{j k}^{n} \mid 0 \leq j, k \leq\right.$ $M, 0 \leq n \leq N\}$ be a grid function on $\Omega_{h} \times \Omega_{\tau}$, and define

$$
\left\{\begin{array}{l}
\delta_{x}^{2} u_{j k}^{n}=\frac{1}{h^{2}}\left(u_{j-1, k}^{n}-2 u_{j k}^{n}+u_{j+1, k}^{n}\right) \\
L_{x} u_{j k}^{n}=\left(I+\frac{h^{2}}{12} \delta_{x}^{2}\right) u_{j k}^{n} .
\end{array}\right.
$$

The notations $\delta_{y}^{2} u_{j k}^{n}$ and $L_{y} u_{j k}^{n}$ can be defined similarly.

Applying the fourth-order Padé scheme for the second-order derivatives, we have

$$
\begin{aligned}
& \frac{\partial^{2} u}{\partial x^{2}}\left(x_{j}, y_{k}, t_{n}\right)=L_{x}^{-1} \delta_{x}^{2} u_{j k}^{n}+O\left(h^{4}\right), \\
& \frac{\partial^{2} u}{\partial y^{2}}\left(x_{j}, y_{k}, t_{n}\right)=L_{y}^{-1} \delta_{y}^{2} u_{j k}^{n}+O\left(h^{4}\right) .
\end{aligned}
$$

Using (3.5) and (3.6), we can obtain the following semi-discrete fourth-order approximation for the $2 \mathrm{D}$ problem (3.1):

$$
i\left[{ }_{0}^{C} \mathcal{D}_{t}^{\alpha} u\right]_{j k}^{n}=L_{x}^{-1} \delta_{x}^{2} u_{j k}^{n}+L_{y}^{-1} \delta_{y}^{2} u_{j k}^{n}+f_{j k}^{n}+O\left(h^{4}\right)
$$

Thus, by using Lemma 2.1 for (3.7) and neglecting the small truncation errors, we obtain the following scheme:

$$
\begin{aligned}
& \frac{i}{\tau^{\alpha} \Gamma(2-\alpha)}\left[a_{0} u_{j k}^{n}-\sum_{l=1}^{n-1}\left(a_{n-l-1}-a_{n-l}\right) u_{j k}^{l}-a_{n-1} u_{j k}^{0}\right] \\
& =L_{x}^{-1} \delta_{x}^{2} u_{j k}^{n}+L_{y}^{-1} \delta_{y}^{2} u_{j k}^{n}+f_{j k}^{n} .
\end{aligned}
$$

Act with the operator $\left(-i \tau^{\alpha} \Gamma(2-\alpha)\right) L_{x} L_{y}$ on both sides of (3.8). By noting that $a_{0}=1$, after rearranging the terms we have the equivalent forms

$$
\begin{aligned}
& {\left[L_{x} L_{y}+i \tau^{\alpha} \Gamma(2-\alpha)\left(\delta_{x}^{2} L_{y}+\delta_{y}^{2} L_{x}\right)\right] u_{j k}^{n}} \\
& \quad=L_{x} L_{y}\left[\sum_{l=1}^{n-1}\left(a_{n-l-1}-a_{n-l}\right) u_{j k}^{l}+a_{n-1} u_{j k}^{0}\right]-i \tau^{\alpha} \Gamma(2-\alpha) L_{x} L_{y} f_{j k}^{n} .
\end{aligned}
$$


Next we consider the derivation of the ADI difference scheme so that some small splitting terms should be added onto the left-hand side of (3.9) in order to achieve the operator splitting scheme. By adding the splitting term

$$
\left[i \tau^{\alpha} \Gamma(2-\alpha)\right]^{2} \delta_{x}^{2} \delta_{y}^{2}\left(u_{j k}^{n}-u_{j k}^{n-1}\right)
$$

to the left-hand side of (3.9) and rearranging the terms of the resulting scheme, we obtain an approximate scheme for $n>1$ as follows:

$$
\begin{aligned}
\left(L_{x}+\right. & \left.i \tau^{\alpha} \Gamma(2-\alpha) \delta_{x}^{2}\right)\left(L_{y}+i \tau^{\alpha} \Gamma(2-\alpha) \delta_{y}^{2}\right) u_{j k}^{n} \\
= & L_{x} L_{y}\left[\sum_{l=1}^{n-1}\left(a_{n-l-1}-a_{n-l}\right) u_{j k}^{l}+a_{n-1} u_{j k}^{0}\right] \\
& +\left[i \tau^{\alpha} \Gamma(2-\alpha)\right]^{2} \delta_{x}^{2} \delta_{y}^{2} u_{j k}^{n-1}-i \tau^{\alpha} \Gamma(2-\alpha) L_{x} L_{y} f_{j k}^{n}
\end{aligned}
$$

Introducing the intermediate variables $u^{1(*)}$ and $u^{n(*)}$, we can obtain the following highorder compact ADI scheme $(C S 2 D I)$ for (3.1)-(3.3):

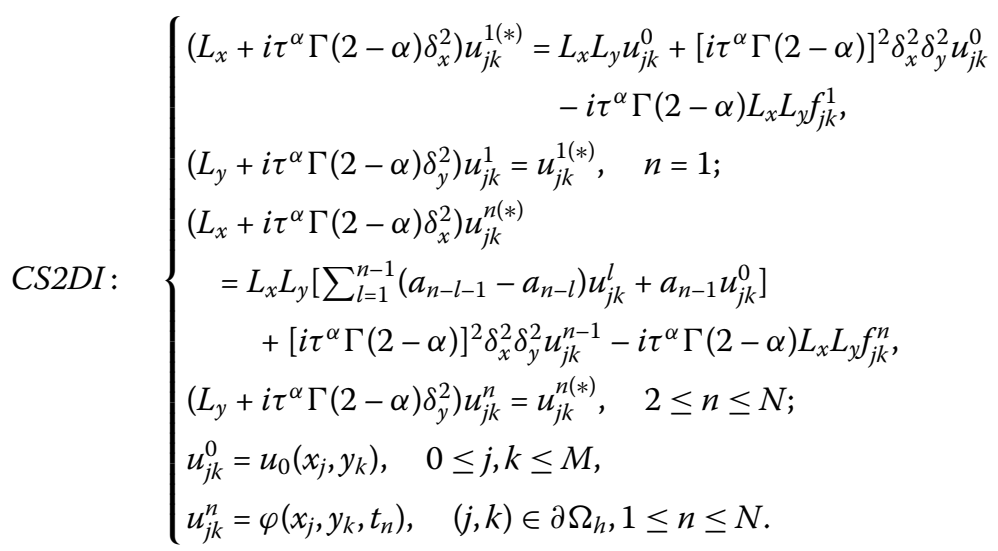

To solve (3.11), we need to give the values of $u^{1(*)}$ and $u^{n(*)}$ on the boundary, and these are obtained from the second and fourth equation in (3.11), respectively.

Now, we present the second difference scheme for (3.1)-(3.3). Using Lemma 2.2 for (3.7) and omitting the small terms, the second difference scheme can be given in the form of

$$
\begin{aligned}
& \frac{i}{\tau^{\alpha} \Gamma(2-\alpha)}\left[c_{0} u_{j k}^{n}-\sum_{l=1}^{n-1}\left(c_{n-l-1}-c_{n-l}\right) u_{j k}^{l}-c_{n-1} u_{j k}^{0}\right] \\
& =L_{x}^{-1} \delta_{x}^{2} u_{j k}^{n}+L_{y}^{-1} \delta_{y}^{2} u_{j k}^{n}+f_{j k}^{n} .
\end{aligned}
$$

By acting on both sides of (3.12) with the operator $\left(\frac{-i \tau^{\alpha} \Gamma(2-\alpha)}{c_{0}}\right) L_{x} L_{y}$ and rearranging the terms, we obtain

$$
\left[L_{x} L_{y}+\frac{i \tau^{\alpha} \Gamma(2-\alpha)}{c_{0}}\left(\delta_{x}^{2} L_{y}+\delta_{y}^{2} L_{x}\right)\right] u_{j k}^{n}
$$




$$
\begin{aligned}
= & L_{x} L_{y}\left[\sum_{l=1}^{n-1} \frac{c_{n-l-1}-c_{n-l}}{c_{0}} u_{j k}^{l}+\frac{c_{n-1}}{c_{0}} u_{j k}^{0}\right] \\
& -\frac{i \tau^{\alpha} \Gamma(2-\alpha)}{c_{0}} L_{x} L_{y} f_{j k}^{n} .
\end{aligned}
$$

By adding the splitting term $\left(\frac{i \tau^{\alpha} \Gamma(2-\alpha)}{c_{0}}\right)^{2} \delta_{x}^{2} \delta_{y}^{2}\left(u_{j k}^{n}-u_{j k}^{n-1}\right)$ to the left-hand side of (3.13) and rearranging the terms of the resulting scheme, we obtain the following scheme for $n>1$ :

$$
\begin{aligned}
\left(L_{x}\right. & \left.+\frac{i \tau^{\alpha} \Gamma(2-\alpha)}{c_{0}} \delta_{x}^{2}\right)\left(L_{y}+\frac{i \tau^{\alpha} \Gamma(2-\alpha)}{c_{0}} \delta_{y}^{2}\right) u_{j k}^{n} \\
= & L_{x} L_{y}\left[\sum_{l=1}^{n-1} \frac{c_{n-l-1}-c_{n-l}}{c_{0}} u_{j k}^{l}+\frac{c_{n-1}}{c_{0}} u_{j k}^{0}\right] \\
& +\left[\frac{i \tau^{\alpha} \Gamma(2-\alpha)}{c_{0}}\right]^{2} \delta_{x}^{2} \delta_{y}^{2} u_{j k}^{n-1}-\frac{i \tau^{\alpha} \Gamma(2-\alpha)}{c_{0}} L_{x} L_{y} f_{j k}^{n} .
\end{aligned}
$$

Upon introducing the intermediate variables $u^{1(*)}$ and $u^{n(*)}$ and noticing that $c_{0}=1$ for $n=1$, we obtain the following additional high-order compact ADI scheme (CS2DII) for (3.1)-(3.3):

$$
\text { CS2DII : }\left\{\begin{array}{c}
\left(L_{x}+i \tau^{\alpha} \Gamma(2-\alpha) \delta_{x}^{2}\right) u_{j k}^{1(*)} \\
=L_{x} L_{y} u_{j k}^{0}+\left[i \tau^{\alpha} \Gamma(2-\alpha)\right]^{2} \delta_{x}^{2} \delta_{y}^{2} u_{j k}^{0}-i \tau^{\alpha} \Gamma(2-\alpha) L_{x} L_{x} f_{j k}^{1} \\
\left(L_{y}+i \tau^{\alpha} \Gamma(2-\alpha) \delta_{y}^{2}\right) u_{j k}^{1}=u_{j k}^{1(*)}, \quad n=1 \\
\left(L_{x}+\frac{i \tau^{\alpha} \Gamma(2-\alpha)}{c_{0}} \delta_{x}^{2}\right) u_{j k}^{n(*)} \\
=L_{x} L_{y}\left[\sum_{l=1}^{n-1} \frac{c_{n-l-1}-c_{n-l}}{c_{0}} u_{j k}^{l}+\frac{c_{n-1}}{c_{0}} u_{j k}^{0}\right] \\
\quad+\left[\frac{i \tau^{\alpha} \Gamma(2-\alpha)}{c_{0}}\right]^{2} \delta_{x}^{2} \delta_{y}^{2} u_{j k}^{n-1}-\frac{i \tau^{\alpha} \Gamma(2-\alpha)}{c_{0}} L_{x} L_{y} f_{j k}^{n} \\
\left(L_{y}+\frac{i \tau^{\alpha} \Gamma(2-\alpha)}{c_{0}} \delta_{y}^{2}\right) u_{j k}^{n}=u_{j k}^{n(*)}, \quad 2 \leq n \leq N \\
u_{j k}^{0}=u_{0}\left(x_{j}, y_{k}\right), \quad 0 \leq j, k \leq M \\
u_{j k}^{n}=\varphi\left(x_{j}, y_{k}, t_{n}\right), \quad(j, k) \in \partial \Omega_{h}, 1 \leq n \leq N
\end{array}\right.
$$

To solve (3.15), we need to give the values of $u^{1(*)}$ and $u^{n(*)}$ on the boundary, and these are obtained from the second and fourth equations in (3.15), respectively.

From (3.7), it is obvious that schemes CS2DI and CS2DII can maintain fourth-order accuracy in space, and from Lemmas 2.1 and 2.2 we know that schemes (3.9) and (3.13) have temporal convergence rates of $O\left(\tau^{2-\alpha}\right)$ and $O\left(\tau^{3-\alpha}\right)$, respectively. We note the fact that if the splitting errors are much larger than the truncation error, as pointed out by Douglas and Kim [32], a splitting term will play an important role in the accuracy of the solution. This phenomenon has also been pointed out by Zhai et al. [33]. From the splitting term $\left[i \tau^{\alpha} \Gamma(2-\alpha)\right]^{2} \delta_{x}^{2} \delta_{y}^{2}\left(u_{j k}^{n}-u_{j k}^{n-1}\right)$, we find that the splitting errors are $O\left(\tau^{2 \alpha+1}\right)$ in schemes $C S 2 D I$ and CS2DII, respectively. This means that the temporal convergence rates for these schemes will tend to $\alpha+1$. The numerical results in Sect. 4 further confirm this judgment.

In the following, we investigate the stability of the high-order compact ADI schemes (CS2DI and CS2DII) using the Fourier analysis method. Here, in order to simplify the notations and without loss of generality, we consider the case that $f(x, y, t)=0$. 
Suppose that the numerical solution is represented by

$$
u_{j k}^{n}=v^{n} e^{i\left(\theta_{x} j h+\theta_{y} k h\right)},
$$

where $i=\sqrt{(-1)}, v^{n}$ is the amplitude at time $t_{n}$, and $\theta_{x}, \theta_{y}$ are the wave numbers in the $x$ and $y$ directions, respectively. We define the discrete $L^{2}$ norm by $\left\|u^{n}\right\|_{L^{2}}^{2}=h^{2} \sum_{j=1}^{M} \sum_{k=1}^{M}\left|u_{j k}^{n}\right|^{2}$. For the fully discrete schemes CS2DI and CS2DII, we have the following stability results.

Theorem 2 Schemes CS2DI and CS2DII, defined by (3.11) and (3.15) respectively, are unconditionally stable for $\alpha \in(0,1)$.

Proof We apply mathematical induction to complete the proof. For convenience, we only give the proof for scheme CS2DI, and the case for scheme CS2DII can be completed using a similar idea.

First, we rewrite (3.11) as

$$
\begin{gathered}
\left(L_{x}+i \tau^{\alpha} \Gamma(2-\alpha) \delta_{x}^{2}\right)\left(L_{y}+i \tau^{\alpha} \Gamma(2-\alpha) \delta_{y}^{2}\right) u_{j k}^{1} \\
=L_{x} L_{y} u_{j k}^{0}+\left[i \tau^{\alpha} \Gamma(2-\alpha)\right]^{2} \delta_{x}^{2} \delta_{y}^{2} u_{j k}^{0}
\end{gathered}
$$

for $n=1$, and for $2 \leq n \leq N$, we write this as follows:

$$
\begin{aligned}
\left(L_{x}+\right. & \left.i \tau^{\alpha} \Gamma(2-\alpha) \delta_{x}^{2}\right)\left(L_{y}+i \tau^{\alpha} \Gamma(2-\alpha) \delta_{y}^{2}\right) u_{j k}^{n} \\
= & L_{x} L_{y}\left[\sum_{l=1}^{n-1}\left(a_{n-l-1}-a_{n-l}\right) u_{j k}^{l}+a_{n-1} u_{j k}^{0}\right] \\
& +\left[i \tau^{\alpha} \Gamma(2-\alpha)\right]^{2} \delta_{x}^{2} \delta_{y}^{2} u_{j k}^{n-1} .
\end{aligned}
$$

Substituting (3.16) into (3.17) and (3.18) and denoting $r=\tau^{\alpha} \Gamma(2-\alpha) / h^{2}, s_{1}=\sin ^{2} \frac{\theta_{x} h}{2}$, and $s_{2}=\sin ^{2} \frac{\theta_{y} h}{2}$ for simplicity, where $0 \leq s_{1}, s_{2} \leq 1$, for $n=1$ we obtain

$$
\begin{gathered}
{\left[\left(1-\frac{1}{3} s_{1}\right)-4 i r s_{1}\right]\left[\left(1-\frac{1}{3} s_{2}\right)-4 i r s_{2}\right] v^{1}} \\
\quad=\left[\left(1-\frac{1}{3} s_{1}\right)\left(1-\frac{1}{3} s_{2}\right)-16 r^{2} s_{1} s_{2}\right] v^{0},
\end{gathered}
$$

and for $2 \leq n \leq N$ we obtain

$$
\begin{aligned}
& {\left[\left(1-\frac{1}{3} s_{1}\right)-4 i r s_{1}\right]\left[\left(1-\frac{1}{3} s_{2}\right)-4 i r s_{2}\right] v^{n}} \\
& =\left(1-\frac{1}{3} s_{1}\right)\left(1-\frac{1}{3} s_{2}\right)\left[\sum_{l=1}^{n-1}\left(a_{n-l-1}-a_{n-l}\right) v^{l}+a_{n-1} v^{0}\right]-16 r^{2} s_{1} s_{2} v^{n-1} \\
& =\left[\left(1-\frac{1}{3} s_{1}\right)\left(1-\frac{1}{3} s_{2}\right)\left(1-a_{1}\right)-16 r^{2} s_{1} s_{2}\right] v^{n-1} \\
& \quad+\left(1-\frac{1}{3} s_{1}\right)\left(1-\frac{1}{3} s_{2}\right)\left[\sum_{l=1}^{n-2}\left(a_{n-l-1}-a_{n-l}\right) v^{l}+a_{n-1} v^{0}\right] .
\end{aligned}
$$


Consequently, we have

$$
\left\{\begin{aligned}
v^{1}= & \frac{\left(1-\frac{1}{3} s_{1}\right)\left(1-\frac{1}{3} s_{2}\right)-16 r^{2} s_{1} s_{2}}{\left(1-\frac{1}{3} s_{1}\right)\left(1-\frac{1}{3} s_{2}\right)-16 r^{2} s_{1} s_{2}-i\left[4 r s_{2}\left(1-\frac{1}{3} s_{1}\right)+4 r s_{1}\left(1-\frac{1}{3} s_{2}\right)\right]} v^{0} \equiv \mu_{0} v^{0} \\
v^{n}= & \frac{\left(1-\frac{1}{3} s_{1}\right)\left(1-\frac{1}{3} s_{2}\right)\left(1-a_{1}\right)-16 r^{2}+s_{1} s_{2}}{\left(1-\frac{1}{3} s_{1}\right)\left(1-\frac{1}{3} s_{2}\right)-16 r^{2} s_{1} s_{2}-i\left[4 r s_{2}\left(1-\frac{1}{3} s_{1}\right)+4 r s_{1}\left(1-\frac{1}{3} s_{2}\right)\right]} v^{n-1} \\
& +\frac{\left(1-\frac{1}{3} s_{1}\right)\left(1-\frac{1}{3} s_{2}\right)}{\left[\left(1-\frac{1}{3} s_{1}\right)-4 i r r_{1}\right]\left[\left(1-\frac{1}{3} s_{2}\right)-4 i r s_{2}\right]}\left[\sum_{l=1}^{n-2}\left(a_{n-l-1}-a_{n-l}\right) v^{l}+a_{n-1} v^{0}\right] \\
2 & \leq n \leq N .
\end{aligned}\right.
$$

We note that $0 \leq s_{1}, s_{2} \leq 1$, and from the first equation of (3.19) we can easily see that $0 \leq\left|\mu_{0}\right| \leq 1$. Therefore,

$$
\left|v_{1}\right|=\left|\mu_{0}\right|\left|v_{0}\right| \leq\left|v_{0}\right|
$$

Assume that we have proved that

$$
\left|v^{m}\right| \leq\left|v^{0}\right|, \quad m=1,2, \ldots, n-1
$$

Then, applying Lemma 2.1 and (3.19), we obtain

$$
\begin{aligned}
\left|v^{n}\right| \leq & \frac{\left|\left(1-\frac{1}{3} s_{1}\right)\left(1-\frac{1}{3} s_{2}\right)\left(1-a_{1}\right)-16 r^{2} s_{1} s_{2}\right|}{\left|\left(1-\frac{1}{3} s_{1}\right)\left(1-\frac{1}{3} s_{2}\right)-16 r^{2} s_{1} s_{2}-i\left[4 r s_{2}\left(1-\frac{1}{3} s_{1}\right)+4 r s_{1}\left(1-\frac{1}{3} s_{2}\right)\right]\right|}\left|v^{n-1}\right| \\
& +\frac{\left|\left(1-\frac{1}{3} s_{1}\right)\left(1-\frac{1}{3} s_{2}\right)\right|}{\left|\left[\left(1-\frac{1}{3} s_{1}\right)-4 i r s_{1}\right]\left[\left(1-\frac{1}{3} s_{2}\right)-4 i r s_{2}\right]\right|}\left[\sum_{l=1}^{n-2}\left(a_{n-l-1}-a_{n-l}\right)\left|v^{l}\right|+a_{n-1}\left|v^{0}\right|\right] \\
\leq & \frac{\left|\left(1-\frac{1}{3} s_{1}\right)\left(1-\frac{1}{3} s_{2}\right)\left(1-a_{1}\right)-16 r^{2} s_{1} s_{2}\right|}{\left|\left(1-\frac{1}{3} s_{1}\right)\left(1-\frac{1}{3} s_{2}\right)-16 r^{2} s_{1} s_{2}-i\left[4 r s_{2}\left(1-\frac{1}{3} s_{1}\right)+4 r s_{1}\left(1-\frac{1}{3} s_{2}\right)\right]\right|}\left|v^{0}\right| \\
& +\frac{\left|\left(1-\frac{1}{3} s_{1}\right)\left(1-\frac{1}{3} s_{2}\right) a_{1}\right|}{\left|\left(1-\frac{1}{3} s_{1}\right)-4 i r s_{1}\right|\left|\left(1-\frac{1}{3} s_{2}\right)-4 i r s_{2}\right|}\left|v^{0}\right|,
\end{aligned}
$$

and it is not difficult to prove that the following inequalities hold:

$$
\begin{aligned}
& \left|\left(1-\frac{1}{3} s_{1}\right)\left(1-\frac{1}{3} s_{2}\right)-16 r^{2} s_{1} s_{2}-i\left[4 r s_{2}\left(1-\frac{1}{3} s_{1}\right)+4 r s_{1}\left(1-\frac{1}{3} s_{2}\right)\right]\right| \\
& \quad \geq\left|\left(1-\frac{1}{3} s_{1}\right)\left(1-\frac{1}{3} s_{2}\right)\left(1-a_{1}\right)-16 r^{2} s_{1} s_{2}\right|
\end{aligned}
$$

and

$$
\left|\left(1-\frac{1}{3} s_{1}\right)-4 i r s_{1}\right|\left|\left(1-\frac{1}{3} s_{2}\right)-4 i r s_{2}\right| \geq\left|\left(1-\frac{1}{3} s_{1}\right)\left(1-\frac{1}{3} s_{2}\right) a_{1}\right| .
$$

That is,

$$
\left|v^{n}\right| \leq\left|v^{0}\right|
$$

holds for all $m=n$. Furthermore, using (3.20) and Parseval's equality, we obtain

$$
\left\|u^{n}\right\|_{L^{2}}^{2}=h^{2} \sum_{j=1}^{M} \sum_{k=1}^{M}\left|u_{j k}^{n}\right|^{2}=h^{2} \sum_{j=1}^{M} \sum_{k=1}^{M}\left|v^{n} e^{i\left(\theta_{x} j h+\theta_{y} k h\right)}\right|^{2}=h^{2} \sum_{j=1}^{M} \sum_{k=1}^{M}\left|v^{n}\right|^{2}
$$




$$
\begin{aligned}
& \leq h^{2} \sum_{j=1}^{M} \sum_{k=1}^{M}\left|v^{0}\right|^{2}=h^{2} \sum_{j=1}^{M} \sum_{k=1}^{M}\left|v^{0} e^{i\left(\theta_{x} j h+\theta_{y} k h\right)}\right|^{2}=h^{2} \sum_{j=1}^{M} \sum_{k=1}^{M}\left|u_{j k}^{0}\right|^{2} \\
& =\left\|u^{0}\right\|_{L^{2}}^{2}, \quad n=1, \ldots, N,
\end{aligned}
$$

and the proof is completed.

\section{Numerical results}

In this section, three numerical examples, which verify the efficiency and accuracy of the proposed schemes, are presented.

Example 1 Let us consider the following 1D time-fractional Schrödinger equation:

$$
\left\{\begin{array}{l}
i \frac{\partial^{\alpha} u(x, t)}{\partial t^{\alpha}}=\frac{\partial^{2} u(x, t)}{\partial x^{2}}+f(x, t), \\
f(x, t)=(1+i) t^{2} \pi^{2} \sin \pi x+\frac{2 t^{2-\alpha}}{\Gamma(3-\alpha)}(i-1) \sin \pi x, \\
x \in \Omega=[0,2], t \in(0,1),
\end{array}\right.
$$

with the exact solution $u(x, t)=(1+i) t^{2} \sin \pi x$. The initial and boundary conditions can be obtained from the exact solution.

Now, we investigate the spatial convergence rates for schemes CS1DI and CS1DII. We choose $N=1000$ to avoid the influence of the temporal approximation. Table 1 gives the $L^{\infty}$-norm errors (denoted by $L^{\infty}$-error) and convergence orders at time $T=1$ for $\alpha=0.25$ (or $\alpha=0.5$ ) and various values of $N_{x}$. From Table 1, we conclude that schemes CS1DI and CS1DII are verified to have fourth-order accuracy in space. Regarding the time accuracy, by fixing $N_{x}$ to eliminate the contamination of the spatial error, the numerical results at $T=1$ for different $\alpha$ and $N$ values are presented in Table 2 . In Fig. 1, we also present the errors in the $L^{\infty}$-norm and $L^{2}$-norm as a function of the time step sizes for $\alpha=0.25$, where $N_{x}=50$ in scheme CS1DI and $N_{x}=250$ in scheme CS1DII. From these results, we find that the convergence order in time for schemes CS1DI and CS1DII is close to $2-\alpha$ and $3-\alpha$, respectively.

\begin{tabular}{|c|c|c|c|c|c|}
\hline \multirow[t]{2}{*}{$\alpha$} & \multirow[t]{2}{*}{$N_{x}$} & \multicolumn{2}{|c|}{ Scheme CSIDI } & \multicolumn{2}{|c|}{ Scheme CSIDII } \\
\hline & & $L^{\infty}$-error & Order & $L^{\infty}$-error & Order \\
\hline 0.25 & $\begin{array}{r}4 \\
8 \\
16 \\
32\end{array}$ & $\begin{array}{l}0.0394 \\
2.281 \mathrm{e}-3 \\
1.399 \mathrm{e}-4 \\
8.700 \mathrm{e}-6\end{array}$ & $\begin{array}{l}- \\
4.111 \\
4.027 \\
4.008\end{array}$ & $\begin{array}{l}0.0394 \\
2.281 \mathrm{e}-3 \\
1.400 \mathrm{e}-4 \\
8.707 \mathrm{e}-6\end{array}$ & $\begin{array}{l}- \\
4.111 \\
4.027 \\
4.007\end{array}$ \\
\hline 0.5 & $\begin{array}{r}4 \\
8 \\
16 \\
32\end{array}$ & $\begin{array}{l}0.0393 \\
2.278 \mathrm{e}-3 \\
1.396 \mathrm{e}-4 \\
8.752 \mathrm{e}-6\end{array}$ & $\begin{array}{l}- \\
4.111 \\
4.029 \\
3.995\end{array}$ & $\begin{array}{l}0.0393 \\
2.278 \mathrm{e}-3 \\
1.397 \mathrm{e}-4 \\
8.694 \mathrm{e}-6\end{array}$ & $\begin{array}{l}- \\
4.110 \\
4.027 \\
4.007\end{array}$ \\
\hline
\end{tabular}

Table 1 Numerical comparison results of schemes CS1D/ and CS1D/l for Example 1, at $T=1$ with $N=1000$ and different $N_{x}$ and $\alpha$ 
Table 2 Numerical comparison results of schemes CS1D/ and CS1D/l for Example 1, at $T=1$ with $N_{x}=2000$ and different $N$ and $\alpha$

\begin{tabular}{|c|c|c|c|c|c|}
\hline \multirow[t]{2}{*}{$\alpha$} & \multirow[t]{2}{*}{$N$} & \multicolumn{2}{|c|}{ Scheme CS1DI } & \multicolumn{2}{|c|}{ Scheme CS1DII } \\
\hline & & $L^{\infty}$-error & Order & $L^{\infty}$-error & Order \\
\hline 0.1 & $\begin{array}{l}10 \\
20 \\
40 \\
80\end{array}$ & $\begin{array}{l}1.554 \mathrm{e}-4 \\
4.563 \mathrm{e}-5 \\
1.322 \mathrm{e}-5 \\
3.793 \mathrm{e}-6\end{array}$ & $\begin{array}{l}- \\
1.768 \\
1.787 \\
1.802\end{array}$ & $\begin{array}{l}2.365 \mathrm{e}-6 \\
2.871 \mathrm{e}-7 \\
3.538 \mathrm{e}-8 \\
4.391 \mathrm{e}-9\end{array}$ & $\begin{array}{l}- \\
3.042 \\
3.021 \\
3.010\end{array}$ \\
\hline 0.5 & $\begin{array}{l}10 \\
20 \\
40 \\
80\end{array}$ & $\begin{array}{l}0.0020 \\
7.191 \mathrm{e}-4 \\
2.577 \mathrm{e}-4 \\
9.199 \mathrm{e}-5\end{array}$ & $\begin{array}{l}- \\
1.472 \\
1.480 \\
1.486\end{array}$ & $\begin{array}{l}8.694 \mathrm{e}-6 \\
1.188 \mathrm{e}-6 \\
1.830 \mathrm{e}-7 \\
3.130 \mathrm{e}-8\end{array}$ & $\begin{array}{l}- \\
2.872 \\
2.699 \\
2.547\end{array}$ \\
\hline 0.9 & $\begin{array}{l}10 \\
20 \\
40 \\
80\end{array}$ & $\begin{array}{l}9.995 \mathrm{e}-3 \\
4.699 \mathrm{e}-3 \\
2.139 \mathrm{e}-3 \\
9.592 \mathrm{e}-4\end{array}$ & $\begin{array}{l}- \\
1.089 \\
1.136 \\
1.157\end{array}$ & $\begin{array}{l}1.334 \mathrm{e}-3 \\
5.067 \mathrm{e}-4 \\
1.272 \mathrm{e}-4 \\
2.840 \mathrm{e}-5\end{array}$ & $\begin{array}{l}- \\
1.397 \\
1.995 \\
2.162\end{array}$ \\
\hline
\end{tabular}
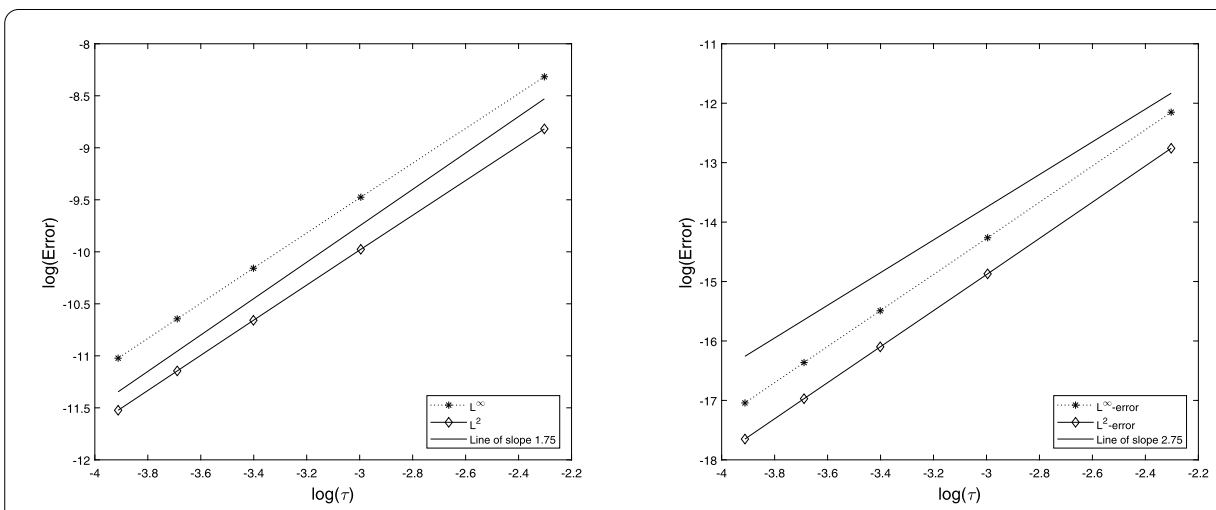

Figure 1 Time errors as a function of the time step sizes with $\alpha=0.25$ for Example 1. (a) Scheme CS1DI, (b) scheme CS1DII

Example 2 Here, we consider the alternative 1D time-fractional Schrödinger equation

$$
\left\{\begin{array}{l}
i \frac{\partial^{\alpha} u(x, t)}{\partial t^{\alpha}}=\frac{\partial^{2} u(x, t)}{\partial x^{2}}+f(x, t), \\
f(x, t)=i\left(\frac{2 t^{2-\alpha} \cos x}{\Gamma(3-\alpha)}+t^{2} \sin x\right)-\frac{2 t^{2-\alpha} \sin x}{\Gamma(3-\alpha)}+t^{2} \cos x \\
\quad x \in \Omega=[0,2 \pi], t \in(0,1) .
\end{array}\right.
$$

The exact solution to the problem is $u(x, t)=t^{2}(\cos x+i \sin x)$. The initial and boundary conditions can be obtained from the exact solution.

In this example, we first use schemes CS1DI and CS1DII to verify the spatial convergence rates. Table 3 presents the $L^{\infty}$-errors and convergence orders with $N=1000$ and various values of $N_{x}$ and $\alpha$ at time $T=1$, from which we find that schemes CS1DI and CS1DII both achieve fourth-order accuracy regardless of the value of $\alpha$. Next, we test the temporal convergence rate for the case that $T=1$ and $N_{x}=2000$. The results for different $N$ and $\alpha$ values are listed in Table 4. In Fig. 2, we plot the errors in the $L^{\infty}$-norm and $L^{2}$ norm as a function of the time step sizes for $N_{x}=50$ in scheme CS1DI and $N_{x}=250$ in scheme CS1DII, where $\alpha=0.75$. It shows that the slopes of the error curves obtained for 
Table 3 Numerical comparison results of schemes CS1DI and CS1D/l for Example 2, at $T=1$ with $N=1000$ and different $N_{x}$ and $\alpha$

\begin{tabular}{|c|c|c|c|c|c|}
\hline \multirow[t]{2}{*}{$\alpha$} & \multirow[t]{2}{*}{$N_{x}$} & \multicolumn{2}{|c|}{ Scheme CSIDI } & \multicolumn{2}{|c|}{ Scheme CS1DII } \\
\hline & & $L^{\infty}$-error & Order & $L^{\infty}$-error & Order \\
\hline \multirow[t]{4}{*}{0.25} & 4 & 0.0218 & - & 0.0218 & - \\
\hline & 8 & $1.277 \mathrm{e}-3$ & 4.094 & $1.277 \mathrm{e}-3$ & 4.093 \\
\hline & 16 & $7.812 \mathrm{e}-5$ & 4.031 & $7.841 \mathrm{e}-5$ & 4.026 \\
\hline & 32 & $4.823 e-6$ & 4.018 & $4.906 \mathrm{e}-6$ & 3.999 \\
\hline \multirow[t]{4}{*}{0.5} & 4 & 0.0181 & - & 0.0181 & - \\
\hline & 8 & $1.056 \mathrm{e}-3$ & 4.096 & $1.062 \mathrm{e}-3$ & 4.089 \\
\hline & 16 & $6.186 e-5$ & 4.094 & $6.624 \mathrm{e}-5$ & 4.003 \\
\hline & 32 & $3.860 \mathrm{e}-6$ & 4.002 & $4.138 e-6$ & 4.001 \\
\hline
\end{tabular}

Table 4 Numerical comparison results of schemes CS1DI and CS1D/l for Example 2, at $T=1$ with $N_{x}=2000$ and different $N$ and $\alpha$

\begin{tabular}{|c|c|c|c|c|c|}
\hline \multirow[t]{2}{*}{$\alpha$} & \multirow[t]{2}{*}{$N$} & \multicolumn{2}{|c|}{ Scheme CS1DI } & \multicolumn{2}{|c|}{ Scheme CS1DII } \\
\hline & & $L^{\infty}$-error & Order & $L^{\infty}$-error & Order \\
\hline 0.1 & $\begin{array}{l}10 \\
20 \\
40 \\
80\end{array}$ & $\begin{array}{l}1.020 \mathrm{e}-3 \\
3.004 \mathrm{e}-4 \\
8.722 \mathrm{e}-5 \\
2.506 \mathrm{e}-5\end{array}$ & $\begin{array}{l}- \\
1.764 \\
1.784 \\
1.800\end{array}$ & $\begin{array}{l}2.044 \mathrm{e}-5 \\
2.537 \mathrm{e}-6 \\
3.212 \mathrm{e}-7 \\
4.115 \mathrm{e}-8\end{array}$ & $\begin{array}{l}- \\
3.010 \\
2.981 \\
2.965\end{array}$ \\
\hline 0.5 & $\begin{array}{l}10 \\
20 \\
40 \\
80\end{array}$ & $\begin{array}{l}0.0154 \\
5.644 \mathrm{e}-3 \\
2.042 \mathrm{e}-3 \\
7.330 \mathrm{e}-4\end{array}$ & $\begin{array}{l}- \\
1.448 \\
1.468 \\
1.478\end{array}$ & $\begin{array}{l}9.402 \mathrm{e}-4 \\
1.602 \mathrm{e}-4 \\
2.786 \mathrm{e}-5 \\
4.886 \mathrm{e}-6\end{array}$ & $\begin{array}{l}- \\
2.553 \\
2.524 \\
2.511\end{array}$ \\
\hline 0.9 & $\begin{array}{l}10 \\
20 \\
40 \\
80\end{array}$ & $\begin{array}{l}0.0889 \\
0.0429 \\
0.0204 \\
9.588 \mathrm{e}-3\end{array}$ & $\begin{array}{l}- \\
1.051 \\
1.074 \\
1.087\end{array}$ & $\begin{array}{l}0.0156 \\
3.679 \mathrm{e}-3 \\
8.439 \mathrm{e}-4 \\
1.968 \mathrm{e}-4\end{array}$ & $\begin{array}{l}- \\
2.086 \\
2.124 \\
2.100\end{array}$ \\
\hline
\end{tabular}
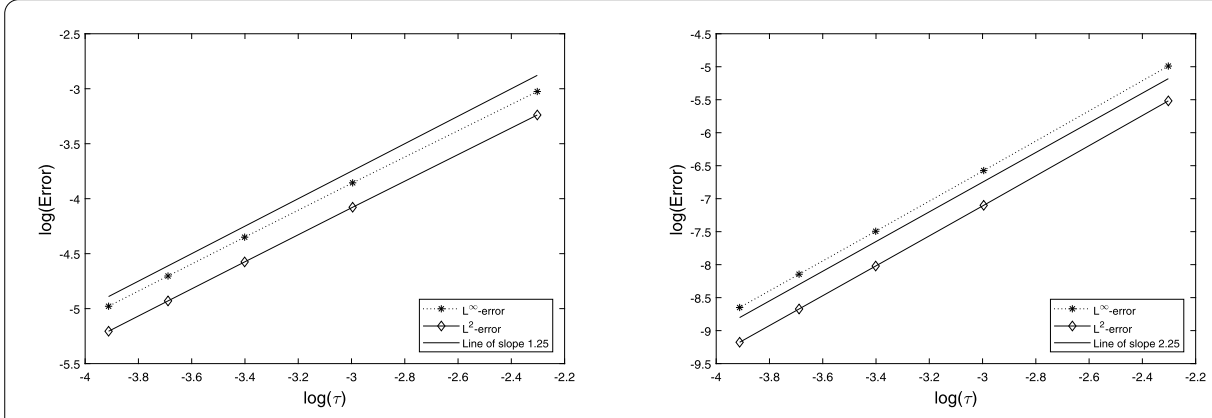

Figure 2 Time errors as a function of the time step sizes with $\alpha=0.75$ for Example 2. (a) Scheme CS1DI, (b) scheme CSIDII

scheme CS1DI is 1.25 , which accords with the theoretical estimates $2-\alpha$. However, scheme CS1DII yields a temporal approximation order 3- $\alpha$, i.e., the slopes of the error curves is 2.25. Again, as expected it is clearly shown that scheme CS1DII has higher accuracy than scheme CS1DI. 
Example 3 We consider the following 2D time-fractional Schrödinger equation:

$$
\left\{\begin{array}{l}
i \frac{\partial^{\alpha^{\alpha} u}}{\partial t^{\alpha}}=\frac{\partial^{2} u}{\partial x^{2}}+\frac{\partial^{2} u}{\partial y^{2}}+f(x, y, t), \\
f(x, y, t)=(1+i)\left(2 t^{2}((1-y) y+(1-x) x)+i(1-x)(1-y) x y \frac{2 t^{2-\alpha}}{\Gamma(3-\alpha)}\right) \\
\quad(x, y) \in \Omega=[0,1] \times[0,1], t \in[0,1] .
\end{array}\right.
$$

Its exact solution is $u(x, y, t)=(1+i)(1-x)(1-y) x y t^{2}$. The initial and boundary conditions of this problem can be extracted from the exact solution.

First, the spatial accuracy is numerically examined. We decrease the mesh size of $h$ to $h / 2$ and $\tau$ to $\tau / 2^{4 / 1+\alpha}$, and the errors and orders for schemes CS2DI and CS2DII are shown in Table 5 for different $\alpha$ values. We can see that the experimental convergence order is approximately four. Second, the numerical accuracy in time is verified. The numerical results at $T=1$ for $\alpha=0.1,0.5$, and 0.9 are listed in Table 6. Meanwhile, the numerical results are plotted in Fig. 3. From these results, we find that schemes CS2DI and CS2DII yield a temporal approximation order close to $1+\alpha$, i.e., the slopes of the error curves are 1.25 and 1.75, respectively, for $\alpha=0.25$ and $\alpha=0.75$. We also plot the contour graphs of the numerical errors using schemes CS2DI and CS2DII with $N=M=100$ for $\alpha=0.1,0.5,0.9$

Table 5 Errors and convergence orders of schemes CS2DI and CS2D/l for Example 3, at $T=1$ with different $\alpha, M$, and $N$

\begin{tabular}{|c|c|c|c|c|c|c|}
\hline \multirow[t]{2}{*}{$\alpha$} & \multirow[t]{2}{*}{ M } & \multirow[t]{2}{*}{$N$} & \multicolumn{2}{|c|}{ Scheme CS2DI } & \multicolumn{2}{|c|}{ Scheme CS2DII } \\
\hline & & & $L^{\infty}$-error & Order & $L^{\infty}$-error & Order \\
\hline 0.25 & $\begin{array}{r}5 \\
10 \\
20\end{array}$ & $\begin{array}{r}50 \\
460 \\
4222\end{array}$ & $\begin{array}{l}5.328 e-3 \\
3.587 e-4 \\
2.247 e-5\end{array}$ & $\begin{array}{l}- \\
3.893 \\
3.997\end{array}$ & $\begin{array}{l}5.277 e-3 \\
3.552 e-4 \\
2.226 e-5\end{array}$ & $\begin{array}{l}- \\
3.892 \\
3.996\end{array}$ \\
\hline 0.5 & $\begin{array}{r}5 \\
10 \\
20\end{array}$ & $\begin{array}{r}50 \\
317 \\
2016\end{array}$ & $\begin{array}{l}1.935 e-3 \\
1.309 e-4 \\
8.175 e-6\end{array}$ & $\begin{array}{l}- \\
3.885 \\
4.002\end{array}$ & $\begin{array}{l}1.911 \mathrm{e}-3 \\
1.293 \mathrm{e}-4 \\
8.075 \mathrm{e}-6\end{array}$ & $\begin{array}{l}- \\
3.885 \\
4.002\end{array}$ \\
\hline 0.75 & $\begin{array}{l}50 \\
10 \\
20\end{array}$ & $\begin{array}{r}50 \\
244 \\
1189\end{array}$ & $\begin{array}{l}7.654 \mathrm{e}-4 \\
5.351 \mathrm{e}-5 \\
3.614 \mathrm{e}-6\end{array}$ & $\begin{array}{l}- \\
3.838 \\
3.888\end{array}$ & $\begin{array}{l}7.580 e-4 \\
5.289 e-5 \\
3.558 e-6\end{array}$ & $\begin{array}{l}- \\
3.841 \\
3.894\end{array}$ \\
\hline
\end{tabular}

Table 6 Numerical comparison results of schemes CS2DI and CS2D/l for Example 3, at $T=1$ with $M=100$ and different $N$ and $\alpha$

\begin{tabular}{|c|c|c|c|c|c|}
\hline \multirow[t]{2}{*}{$\alpha$} & \multirow[t]{2}{*}{$N$} & \multicolumn{2}{|c|}{ Scheme CS1DI } & \multicolumn{2}{|c|}{ Scheme CS1DII } \\
\hline & & $L^{\infty}$-error & Order & $L^{\infty}$-error & Order \\
\hline 0.1 & $\begin{array}{l}10 \\
20 \\
40 \\
80\end{array}$ & $\begin{array}{l}6.742 \mathrm{e}-2 \\
3.129 \mathrm{e}-2 \\
1.393 \mathrm{e}-2 \\
6.438 \mathrm{e}-3\end{array}$ & $\begin{array}{l}- \\
1.107 \\
1.168 \\
1.114\end{array}$ & $\begin{array}{l}6.735 \mathrm{e}-2 \\
3.111 \mathrm{e}-2 \\
1.385 \mathrm{e}-2 \\
6.404 \mathrm{e}-3\end{array}$ & $\begin{array}{l}- \\
1.114 \\
1.168 \\
1.113\end{array}$ \\
\hline 0.5 & $\begin{array}{l}10 \\
20 \\
40 \\
80\end{array}$ & $\begin{array}{l}2.181 \mathrm{e}-2 \\
8.062 \mathrm{e}-3 \\
2.886 \mathrm{e}-3 \\
1.028 \mathrm{e}-3\end{array}$ & $\begin{array}{l}- \\
1.436 \\
1.482 \\
1.489\end{array}$ & $\begin{array}{l}2.141 \mathrm{e}-2 \\
7.964 \mathrm{e}-3 \\
2.850 \mathrm{e}-3 \\
1.015 \mathrm{e}-3\end{array}$ & $\begin{array}{l}- \\
1.427 \\
1.482 \\
1.489\end{array}$ \\
\hline 0.9 & $\begin{array}{l}10 \\
20 \\
40 \\
80\end{array}$ & $\begin{array}{l}9.789 \mathrm{e}-3 \\
2.759 \mathrm{e}-3 \\
7.797 \mathrm{e}-4 \\
2.243 \mathrm{e}-4\end{array}$ & $\begin{array}{l}- \\
1.827 \\
1.823 \\
1.798\end{array}$ & $\begin{array}{l}9.750 e-3 \\
2.747 e-3 \\
7.757 e-4 \\
2.229 e-4\end{array}$ & $\begin{array}{l}- \\
1.828 \\
1.824 \\
1.799\end{array}$ \\
\hline
\end{tabular}



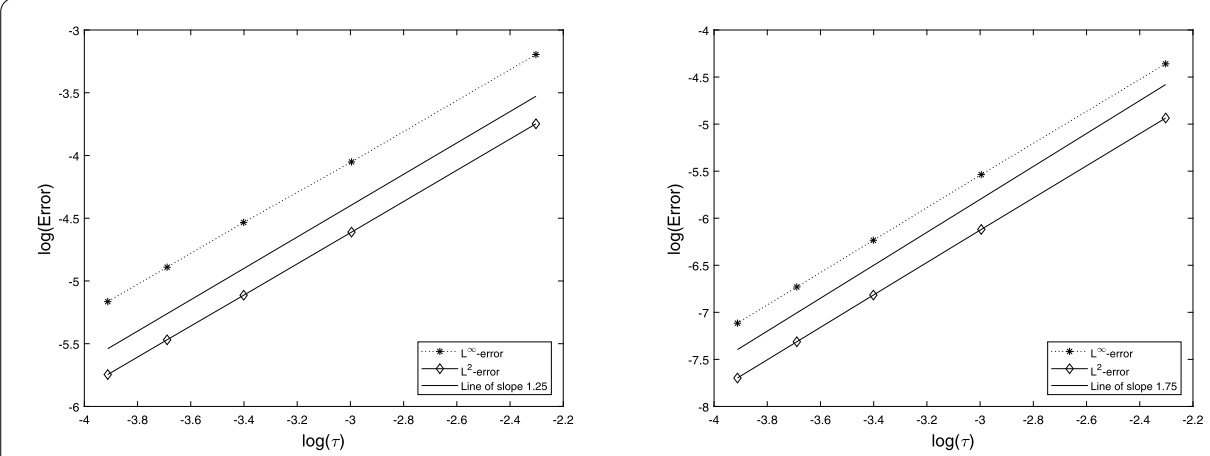

Figure 3 Time errors as a function of the time step sizes for Example 3. (a) Scheme CS2D/ with $\alpha=0.25$, (b) scheme CS2D// with $\alpha=0.75$
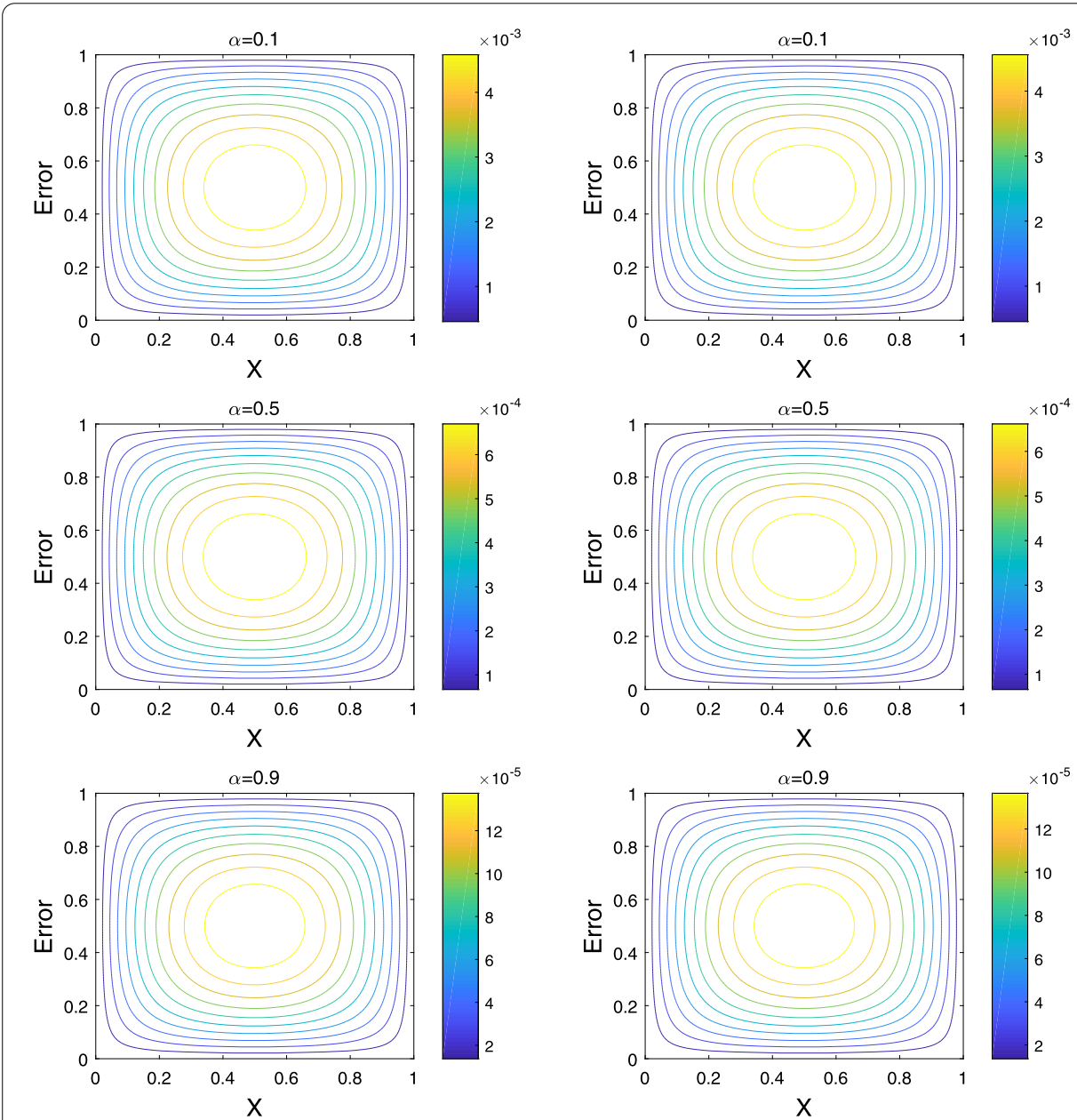

Figure 4 The contour plot of the $L^{\infty}$-error using two schemes at $T=1$, with $N=M=100$, and different $\alpha$ for Example 3. Left panel for scheme CS2DI and right panel for scheme CS2DII, respectively

in Fig. 4. From these results, we find that two methods have the same temporal convergence rates, and the convergence rate of scheme CS2DII is lower than $3-\alpha$ because of the splitting term. 


\section{Conclusions}

In this paper, we have proposed two kinds of high-order compact finite difference schemes with order $O\left(\tau^{2-\alpha}+h^{4}\right)$ and $O\left(\tau^{3-\alpha}+h^{4}\right)$, respectively, for solving the one-dimensional time-fractional Schrödinger equation. Here, the time discretization is replaced by the $L 1$ and $L 1-2$ formulas, and the space discretization is derived using the high-order compact finite difference method. Then, the extension to the two-dimensional problem is considered. We have designed two high-order compact ADI difference schemes with accuracy $O\left(\tau^{1+\alpha}+h^{4}\right)$. In the two-dimensional case, it is worth noting that the splitting term can affect the local truncation error for the time accuracy. Moreover, both theoretical analysis and numerical examples show that all schemes are unconditionally stable for $\alpha \in(0,1)$ and have the high accuracy. Evidently, the proposed schemes are easy to be implemented and extended to solve other fractional PDEs.

\section{Acknowledgements}

The authors would like to express their sincere thanks to the anonymous referees and associated editor for his/her careful reading of the manuscript.

\section{Funding}

This work is partially supported by the National Natural Science Foundation of China (No. 11801485), the scientific research plan of Universities in Xinjiang (No. XJEDU20201001), and the Key Laboratory of Xinjiang Province (No. 2020D04002).

\section{Availability of data and materials}

Data sharing not applicable to this article as no datasets were generated or analysed during the current study.

\section{Competing interests}

The authors declare that they have no competing interests.

Authors' contributions

All authors have read and approved the final manuscript.

Authors' information

Xinlong Feng, Email: fxlmath@xju.edu.cn; Ehmet Kasim, Email: ehmetkasim@163.com

\section{Publisher's Note}

Springer Nature remains neutral with regard to jurisdictional claims in published maps and institutional affiliations.

Received: 29 May 2020 Accepted: 3 September 2020 Published online: 17 September 2020

\section{References}

1. Uchaikin, V.V.: Fractional Derivatives for Physicistis and Engineers. Higher Education Press, Beijing (2013)

2. Kilbas, A.A., Srivastava, H.M., Trujillo, J.J.: Theory and Applications of Fractional Differential Equations. Elsevier, Boston (2006)

3. Hilfer, R.: Applications of Fractional Calculus in Physics. World Scientific, Singapore (1999)

4. Magine, R.L.: Fractional Calculus in Bioengineering. Begell House Publishers, Redding (2006)

5. Kirchner, J., Feng, X., Neal, C.: Fractal stream chemistry and its implications for contaminant transport in catchments. Nature 403, 524-526 (2000)

6. Agarwal, P., Dragomir, S.S., Jeli, M., Samet, B.: Advances in Mathematical Inequalities and Applications. Springer, Singapore (2018)

7. Scalas, E., Gorenflo, R., Mainardi, F.: Fractional calculus and continuous-time finance. Physica A 284, 376-384 (2000)

8. Singh, J., Kumar, D., Baleanu, D., Rathore, S.: On the local fractional wave equation in fractal strings. Math. Methods Appl. Sci. 42(5), 1588-1595 (2019)

9. Kumar, D., Singh, J., Baleanu, D.: On the analysis of vibration equation involving a fractional derivative with Mittag-Leffler law. Math. Methods Appl. Sci. 43(1), 443-457 (2020)

10. Agarwal, P:: Some inequalities involving Hadamard-type k-fractional integral operators. Math. Methods Appl. Sci. 40(11), 3882-3891 (2017)

11. Singh, J., Kumar, D., Baleanu, D.: A new analysis of fractional fish farm model associated with Mittag-Leffler type kernel. Int. J. Biomath. 13(2), 2050010 (2020)

12. Singh, J., Jassim, H.K., Kumar, D.: An efficient computational technique for local fractional Fokker Planck equation. Physica A 555(1), 124525 (2020)

13. Agarwal, P., Jleli, M., Tomar, M.: Certain Hermite-Hadamard type inequalities via generalized k-fractional integrals. J. Inequal. Appl. 2017(1), 55 (2017) 
14. Wang, G.T., Agarwal, P., Chand, M.: Certain Grüss type inequalities involving the generalized fractional integral operator. J. Inequal. Appl. 2014(1), 147 (2014)

15. Zhuang, P., Liu, F., Anh, V., Turner, I.: Stability and convergence of an implicit numerical method for the non-linear fractional reaction-subdiffusion process. IMA J. Appl. Math. 74, 645-667 (2009)

16. Chen, C.M., Liu, F., Turner, I., Anh, V.: A Fourier method for the fractional diffusion equation describing sub-diffusion. J. Comput. Phys. 227, 886-897 (2007)

17. Brunner, H., Ling, L., Yamamoto, M.: Numerical simulation of 2D fractional subdiffusion problems. J. Comput. Phys. 229, 6613-6622 (2010)

18. Qiao, Y.Y., Zhai, S.Y., Feng, X.L.: RBF-FD method for the high dimensional time fractional convection-diffusion equation. Int. Commun. Heat Mass Transf. 89, 230-240 (2017)

19. Cui, M.R.: Convergence analysis of high-order compact alternating direction implict schemes for the two-dimensional time fractional diffusion equation. Numer. Algorithms 62, 383-409 (2013)

20. Gao, G.H., Sun, H.W.: Three-point combined compact alternating direction implicit difference schemes for two-dimensional time-fractional advection-diffusion equations. Commun. Comput. Phys. 17, 487-509 (2015)

21. Zhai, S.Y., Feng, X.L.: Investigations on several compact ADI methods for the $2 \mathrm{D}$ time fractional diffusion equation. Numer. Heat Transf., Part B, Fundam. 69(4), 364-376 (2016)

22. Mohebbi, A., Abbaszadeh, M., Dehghan, M.: The use of a meshless technique based on collocation and radial basis functions for solving the time fractional nonlinear Schrödinger equation arising in quantum mechanics. Eng. Anal. Bound. Elem. 37(2), 475-485 (2013)

23. Wei, L.L., He, Y.N., Zhang, X.D., Wang, S.L.: Analysis of an implicit fully discrete local discontinuous Galerkin method for the time-fractional Schrödinger equation. Finite Elem. Anal. Des. 59, 28-34 (2012)

24. Li, D.F., Wang, J.L., Zhang, J.W.: Unconditionally convergent L1-Galerkin FEMs for nonlinear time-fractional Schrödinger equations. SIAM J. Sci. Comput. 39(6), A3067-A3088 (2017)

25. Yang, Y., Wang, J.D., Zhang, S.Y., Tohidi, E.: Convergence analysis of space-time Jacobi spectral collocation method for solving time-fractional Schrödinger equations. Appl. Math. Comput. 387, 124489 (2019)

26. Chen, X.L., Di, Y.N., Duan, J.Q., Li, D.F.: Linearized compact ADI schemes for nonlinear time-fractional Schrödinger equations. Appl. Math. Lett. 84, 160-167 (2018)

27. Sun, Z.Z., Wu, X.N.: A fully discrete difference scheme for a diffusion-wave system. Numer. Math. 56, 193-209 (2006)

28. Vong, S., Lyu, P., Wang, Z.: A compact difference scheme for fractional sub-diffusion equations with the spatially variable coefficient under Neumann boundary conditions. J. Sci. Comput. 66, 725-739 (2015)

29. Gao, G.H., Sun, Z.Z., Zhang, H.W.: A new fractional numerical differentiation formula to approximate the Caputo fractional derivative and its applications. J. Comput. Phys. 259, 33-50 (2014)

30. Zhang, Y.N., Sun, Z.Z: Alternating direction implicit schemes for the two-dimensional fractional sub-diffusion equation. J. Comput. Phys. 230, 8713-8728 (2011)

31. Zhao, X., Xu, Q.W.: Efficient numerical schemes for fractional sub-diffusion equation with the spatially variable coefficient. Appl. Math. Model. 38, 3848-3859 (2014)

32. Douglas, J., Kim, S.: Improved accuracy for locally one-dimensional methods for parabolic equations. Math. Models Methods Appl. Sci. 11, 1563-1579 (2001)

33. Zhai, S.Y., Feng, X.L., He, Y.N.: An unconditionally stable compact ADI method for three-dimensional time-fractional convection-diffusion equation. J. Comput. Phys. 269, 138-155 (2014)

\section{Submit your manuscript to a SpringerOpen ${ }^{\circ}$ journal and benefit from:}

- Convenient online submission

- Rigorous peer review

- Open access: articles freely available online

- High visibility within the field

- Retaining the copyright to your article

Submit your next manuscript at $\boldsymbol{~ s p r i n g e r o p e n . c o m ~}$ 